\title{
A NOTE ON SPELLING
}

Changes in the spelling of Indonesian and Dutch names, terms, and words over the past half-century have created a stylistic puzzle in writing this book. The system followed here is: personal and organizational names as well as published titles of monographs, articles, and reports are spelled as in the original; place names and other Indonesian or Dutch words are spelled according to current convention. Thus, the reader will find, for example, the spellings Jepara, Tuban, and Yogyakarta rather than Japara, Toeban, and Jogjakarta or other variants; similarly, variant spellings such as Boschwezen and boswachter are used. 
